\title{
Process simulation and modeling: Anaerobic digestion of complex organic matter
}

Mani, S., Sundaram, J. ${ }^{*}$ and Das, K.C

College of Engineering

University of Georgia

597 Drew Brooks Drive

Athens, GA, 30602

*Corresponding author email: jayas@engr.uga.edu; Phone: 70654238158

\begin{abstract}
This work is focused on evaluating kinetic models of complex organic matters hydrolysis and volatile fatty acids degradation in anaerobic digestion process, simulated using SuperPro design software. Kinetic model evaluation was also carried for simulated integrated system of liquid anaerobic digestion (LAD) of dairy manure and solid state anaerobic digestion (SS-AD) of corn stover. Already developed hydrolysis and volatile fatty acid (VFA) degradation kinetic constants were used to simulate anaerobic digestion processes of dairy manure and corn stover separately and in the integrated process as well. Hydrolysis of complex soluble organic matters such as protein, carbohydrate and fat was modelled using first-order kinetics. Monod model was tested for the VFAs such as acetic, propionic and butyric acid degradation and biogas production. Comparative study has been done between the experimental data published already and results obtained from SuperPro simulated processes. The simulated results were well comparable with the experimental results.
\end{abstract}

Keywords: Anaerobic digestion; LAD; SS-AD; SuperPro process simulation; modeling; VFA degradation; hydrolysis; complex organic matter; kinetics 


\section{Introduction}

Anaerobic digestion of complex organic matter is described as sequential process steps involving hydrolysis, acidogenesis, acetogenesis and methanogenesis. Hydrolysis is often rate limiting when the particulate matter is not readily degradable or in systems with high loading rates. Even though the dynamics of hydrolysis of some individual substrates are known, the process is often described as a simple first-order process due to extensive variations in substrate composition $[1,2]$. The cumulative effects of various processes during hydrolysis were simplified to single first-order kinetics for the substrate biodegradation. However, sometimes relatively high hydrolysis rates were reached in anaerobic biodegradability tests particularly when there is a high inoculum-to substrate ratio. It shows that degree of hydrolysis depends on biomass concentration or their activity. Some of the previously published work says that the first order kinetics of hydrolysis is not applicable in all circumstances. The objective of this paper is to test the first order kinetics for hydrolysis of dairy manure and corn stover constituents to compare their sensitivity to the simulated liquid anaerobic digestion (LAD) and solid state anaerobic digestion (SS-AD) process and the goodness of this model was compared with the available experimental data in the published literatures. A wide range of hydrolysis rate constants of carbohydrates, proteins and fats have been reported assuming first-order hydrolysis. However, it should be taken into account that the substrate hydrolysis rate depends very much on the origin and the previous acclimation of the anaerobic culture.

During anaerobic digestion of organic matter monosaccharides, amino acids and long chain fatty acids, hydrolysis products, volatile fatty acids (acetate, butyrate, propionate, lactate, etc.) and hydrogen are formed. They all are the precursors for methane production. When a process is composed with sequences of reactions, the overall rate is determined by the slowest reaction, 
named the rate-limiting step [3]. Hydrolysis is the rate-limiting step in anaerobic digestion generally [1]. Acidogenesis after hydrolysis is the quickest step during the anaerobic digestion of complex organic material. For efficient methane production it is important to have a balance between the reactions rates of the different steps involved in the anaerobic digestion. Acetate is the main precursor of more than $75 \%$ of methane production during anaerobic digestion [4]. Propionate and Butyrate are other important VFA which are further converted into acetate and hydrogen. Most of the research papers on anaerobic digestion modeling concluded that except hydrolysis other sub process could be modeled successfully using Monod kinetics. Some said that the Haldane kinetic coefficients were much more constant than Monod kinetic coefficients [5]. In this present work Monod kinetic model was tested for VFA degradation and compared with the available experimental data in the published literatures. Kinetic constants of VFA degradation models were collected from the previously published articles [6]. When the anaerobic digestion process is successfully proceeding, the concentration of VFA would be less than $250 \mathrm{mg} / \mathrm{L}$. In order to achieve better digestion process, high acid concentrations that associated with digestion process failure should be avoided. Therefore, continuous degradation of VFA is an essential process to enhance biogas production.

\section{Method}

\subsection{Model development}

The process models were developed using SuperPro designer (Intelligen, Inc., Scotch Palins, NJ) for an anaerobic digestion plant that integrates dairy manure and corn stover for biogas production. The liquid anaerobic digester capacity was designed to handle 250 ton/day of dairy manure with $5 \%$ solid content at the temperature of $37^{\circ} \mathrm{C}$. Biogas production by integrating liquid and solid state anaerobic digestion process was divided into different sections such as 
receiving liquid dairy waste manure, dilution, fiber removal, anaerobic digestion, gas production and effluent storage. Integrated LAD and SS-AD process was designed for corn stover hydrolysis, blending of hydrolyzed corn stover with LAD effluent, feeding this entire mix for digestion, biogas production through anaerobic digestion and collection of digestate for manure purpose. Biogas produced by LAD and SS-AD can be mixed in the process design and then cleaned for separating bio-methane from carbon dioxide, ammonia and hydrogen sulfide mix through gas absorption process using water. Process design for LAD and SS-AD systems were simulated individually and compared with the methane production rate of the integrated system. Kinetic models for hydrolysis and VFA degradation inside the digester were evaluated individually for LAD and SS-AD with LAD effluent.

\subsection{Process design elements of LAD (dairy manure) system}

Manure collection and handling is the key considerations to design an AD system which includes the amount of water and total solids of the manure. Additional solids are added from wasted feed, free stall bedding, and soil tracked in from outside lots. Additional water is added from water wastage, milking center waste water, water used to clean floors, and flushing of alleys. After manure collection, manure pretreatment such as screening, grit removal, mixing, were designed to adjust the manure water and total solid contents. To avoid the mixing of sand and rocks into the digester a concrete or metal mixing tank was used to settle some of the major solids like rocks. Then it was sent through solid separator/screening to remove other solids such as bedding fiber materials. Belt filtration separator was used in the SuperPro simulation model to recover coarse solids and fibers. 
Anaerobic digestion: Anaerobic digestion of complex organic dairy manure involves, hydrolysis, liquefaction, and fermentation; (2) hydrogen and acetic acid formation; (3) methane formation.

At the beginning hydrolysis did take place to reduce complex organic biomass into simple soluble molecules by extracellular enzymes. Proteins, lipids and carbohydrate polymers were hydrolyzed to amino acids, long-chain fatty acids, and sugars, respectively. The reduced compounds were then converted by fermentative bacteria to a mixture of short chain volatile fatty acids (VFAs) and other products such as carbon dioxide, hydrogen and acetic acid. Acetogenic bacteria further converted the organic acids to acetate, carbon dioxide, and/or hydrogen which were the direct substrates for methane production. The final step was methanogenesis, where a variety of methanogenic bacteria consumed acetate, carbon dioxide, and hydrogen to produce methane. Methanogenesis is the focus of many AD studies due to its sensitivity to feedback inhibition by acidic intermediates. The heterogeneous nature of the substrate in SS-AD systems creates more ideal micro-environments for the growth of each microbial family that are required to complete the digestion process. So the culture in fermentation processes behaves quite differently in solid substrates [7].

\section{Hydrolysis, liquefaction, and fermentation:}

Hydrolysis and liquefaction step convert the complex organic materials into nutrient source that can pass through the bacteria cell wall to serve energy for their survival; i.e., Protein, carbohydrate, cellulose, and hemicellulose in the manure are hydrolyzed and metabolized into mainly short-chain fatty acids - acetic, propionic, and butyric — along with $\mathrm{CO}_{2}$ and hydrogen $\left(\mathrm{H}_{2}\right)$ gases. At this stage the decomposition products have noticeable, disagreeable, effusive 
odors from the organic acids, $\mathrm{H}_{2} \mathrm{~S}$, and other metabolic products. Hydrolysis and liquefaction are accomplished by extracellular, hydrolytic enzymes produced and excreted by the bacterial population. Proper functioning of hydrolysis step is more important for the stabilization of complex organic manure. Rate hydrolysis limits the overall rate of stabilization and fermentation. During hydrolysis, there should be sufficient quantity of extracellular hydrolytic enzymes produced by the bacteria, so that it can have intimate contact with complex organics without limiting the overall stabilization reaction. So it is important to maintain the uniform mixing and temperature and concentrated organic substrate and the microbial population inside the digester system. Volatile solids reduction in anaerobic digestion is different in different plants, which depends on the manure characteristics and its upstream processing. Glucose is the most common substrate in anaerobic digestion and it is obtained from hydrolysis of macromolecules such as carbohydrate (polysaccharides). Glucose degradation in anaerobic digestion includes multiple biochemical reactions as given below along with microbial degradation [8].

$$
\begin{aligned}
& \mathrm{C}_{6} \mathrm{H}_{12} \mathrm{O}_{6} \rightarrow \mathrm{CH}_{3} \mathrm{COCOOH}+\mathrm{CH}_{3} \mathrm{COOH}+\mathrm{HCOOH}+\mathrm{C}_{2} \mathrm{H}_{5} \mathrm{OH} \\
& \mathrm{C}_{6} \mathrm{H}_{12} \mathrm{O}_{6}+2 \mathrm{H}_{2} \mathrm{O} \rightarrow 2 \mathrm{CH}_{3} \mathrm{COOH}+4 \mathrm{H}_{2}+2 \mathrm{CO}_{2} \\
& \mathrm{C}_{6} \mathrm{H}_{12} \mathrm{O}_{6}+2 \mathrm{H}_{2} \rightarrow 2 \mathrm{CH}_{3} \mathrm{CH}_{3} \mathrm{COOH}+2 \mathrm{H}_{2} \mathrm{O} \\
& \mathrm{C}_{6} \mathrm{H}_{12} \mathrm{O}_{6} \rightarrow \mathrm{CH}_{3}\left(\mathrm{CH}_{2}\right)_{2} \mathrm{COOH}+2 \mathrm{H}_{2}+2 \mathrm{CO}_{2}
\end{aligned}
$$

After the hydrolysis of complex organics, fermentation takes place on long chain organic acids, sugars, amino acids to convert them in to smaller organic acids such as propionic-, butyric and valeric acid, which is called acid forming phase or fermentation phase. Acetic acid, hydrogen, and carbon dioxide are also formed during the production of organic acids in acid forming phase. Hydrogen is inhibitory to many of the acid-forming bacteria and must be 
removed from the system if acid production is to continue. However, hydrogen is an energy source for some methanogenic bacteria and is rapidly consumed in the reduction of carbon dioxide to methane.

\subsection{Hydrolysis of carbohydrate, protein and fat}

Hydrolysis is the rate limiting step of complex organic matters such as dairy waste. The first order kinetics of complex organic matters is the most conventional model to simulate hydrolysis involves concentration degradation of degradable organic materials such as lipid, protein, and carbohydrate degradation.

$$
\frac{\mathrm{dS}}{\mathrm{dt}}=-\mathrm{k}_{\mathrm{hyd}} \mathrm{S}
$$

Where $S$ is the volatile solids (VS) concentration; $k_{\text {hyd }}$ is the first order coefficient. The kinetic coefficients of the $1^{\text {st }}$ order rate of hydrolysis for different substrates were obtained from literature [9]. The biodegradability of a complex substrate depends on the content of biodegradable carbohydrates (including cellulose, hemicellulose and lignin fractions), proteins and lipids which influences the biogas production potential [10]. Wide range of rate constants for hydrolysis of carbohydrates, proteins and lipids were reported and those assumed first order reaction for hydrolysis. Some of the hydrolysis first order reaction constants from the literature is given in Table 1.

\section{Table 1}

First order kinetic coefficients of hydrolysis from various literatures

\begin{tabular}{l|l|l|l}
\hline Substrate & $\mathbf{k}_{\text {hyd }}\left(\mathbf{d a y}^{-\mathbf{1}}\right)$ & $\mathbf{T}\left({ }^{\circ} \mathbf{C}\right)$ & Reference \\
\hline Carbohydrate & $0.5-2.0$ & 55 & Garcia-Heras, [11] \\
\hline
\end{tabular}




\begin{tabular}{l|l|l|l}
\hline Cattle manure & 0.13 & 55 & Vavilin et al., [11] \\
Proteins & $0.015-0.075$ & 55 & Christ et al., [13] \\
Proteins & $0.25-0.8$ & 55 & Garcia-Heras, [11] \\
Lipids & $0.1-0.7$ & 55 & Garcia-Heras,[11] \\
Lipids & $0.005-0.01$ & 55 & Christ et al., [13] \\
\hline
\end{tabular}

\subsection{SuperPro simulation model of liquid state anaerobic digestion of dairy waste}

In this present study the SuperPro simulated model followed a simple basis to compare stable anaerobic process performance under practical scenario. Fig.1 shows the flow diagram of simulated LAD process of dairy manure. The substrate concentration was correlated with volatile acid production, thus the simulation was done for VFA production with various concentration of substrate volatile solids (VS). Upon simulated hydrolysis, the kinetics of biomass growth and substrate utilization rate were assumed to follow first order reaction kinetics. Simulation of this model has been conducted by studying sensitivity of process variable such as total volatile solids percentage by varying the hydraulic retention time. This model was simulated using typical kinetic data of anaerobic digestion of dairy waste at $37^{\circ} \mathrm{C}$. The hydrolysis rate constants used for carbohydrate, protein and fat are given in Table 2. These constants were selected from the literature and slightly modified to fit the simulated substrate degradation rates. Simulated degradation rates were compared with the already published experimental values of substrate degradation of dairy manure.

\section{Table 2}

Hydrolysis kinetic constants used for simulated SuperPro LAD model organic matter degradation 


\begin{tabular}{l|l|l|l}
\hline Substrate & $\mathbf{k}_{\text {hyd }}\left(\mathbf{h}^{-\mathbf{1}}\right)$ & $\mathbf{T}\left({ }^{\circ} \mathbf{C}\right)$ & Reference \\
\hline Carbohydrate & 0.0469 & 37 & Simeonov et al., [14] \\
Proteins & 0.003125 & 37 & Ruel et al., [15] \\
Fat & 0.0034 & 37 & Ruel et al., [15] \\
\hline
\end{tabular}

2.5. SuperPro simulation model of solid state anaerobic digestion of corn stover

SuperPro simulated model for SS-AD followed a simple basis to compare stable solid state anaerobic process performance of corn stover under practical scenario. Upon simulated hydrolysis, the kinetics of biomass growth and substrate utilization rate were assumed to follow first order reaction kinetics. This model was simulated using typical kinetic data of anaerobic digestion of corn stover to show the volatile fatty acid production rate. The solid state anaerobic digestion hydrolysis rate constants used for carbohydrate and protein are selected from the literature [16]. These constants were slightly modified to fit the simulated substrate degradation and volatile acid production rates. Similarly the process simulation was carried using already developed kinetic model constants for biogas and methane yield and the results were compared with the published experimental values.

\subsubsection{Corn stover pretreatment}

Cellulose, the most abundant carbohydrate in corn stover and it is a fraction of the complex lignocellulosic matrix along with other macromolecules lignin and hemicelluloses. The cellulose macromolecule is composed of glucose units linked together through $\beta 1$,4-glycosidic bonds (or acetyl bonds) creating long chains. These chains combined together and formed fibrils/fibers. A typical fibril will have zones that are crystalline separated by zones that are amorphous. Crystalline form is difficult to disassemble with hydrolyzing agents but amorphous phase has a 
certain level of disorder that makes relatively easy penetration of hydrolyzing agents. Enzymes or ionic species (acid and alkali) are the commonly used hydrolyzing agents. Lignin is other macromolecules found in the lignocellulosic matrix and composed of phenyl propane units bond together via ether bonds. $\mathrm{C}-\mathrm{C}$ bond between moieties are significant in lignocellulosic matrix. Lignin has low oxygen content and a high energetic value. Hemicelluloses are similar to cellulose macromolecules that composed of carbohydrates and extractives are also the macromolecules found in corn stover.

Hydrolysis pre-treatment of feed stocks that are high in cellulose and lignin would increase biogas production and volatile solids reduction [17] also increased solubilization [18]. Pre-treatment breaks down these recalcitrant polymers physically, thermally, or chemically. The key to hydrolysis of cellulose using chemical is to break the hydrogen bonding between the cellulose macromolecules in the fibrils. For this a compound or a mixture of compound that could efficiently rupture the hydrogen bonding is used. The chemical compound should have the capability of penetration in the tight hydrogen bonded ultrastructure. Initial complex structure of cellulose and hemicellulose that are tightly protected with lignin material was converted into simple structure by breaking the lignin wall. Among the various hydrolysis methods alkali treatment is advantageous for plant based organic waste to produce biogas through anaerobic digestion. Alkali treatment has been proved to high cellulose reduction and yield high methane (biogas). Major structural and morphological changes begin to occur in cellulose structure at higher alkali concentrations greater than $6 \%$. By increasing the alkali concentration cellulose crystallite structures will swell and it starts at amorphous region and then to crystalline region. So, there will be decrease in degree of polymerization (DP) and degree of crystallinity (CrI; 
crystallinity index) with increase in alkali concentration $[19,20]$. Therefore alkali $(\mathrm{NaOH})$ was used in the simulated SS-AD process to pretreat the corn stover.

\subsection{SuperPro simulation model of integrated solid- liquid state anaerobic digestion of dairy} waste and corn stover

Animal manure, sewage sludge, and food waste are treated by liquid AD. Majority of dairy farm scale digesters in US are completely stirred tank liquid state anaerobic reactor (LAD). It produces large amount of effluent and it needs to be disposed after digestion. It has strong odor and creates environmental issues. Organic fractions of municipal solid waste and lignocellulosic biomass such as crop residues and energy crops are processed through SS-AD.

Advantages of SS-AD include smaller reactor capacity requirements, less energy used for heating, and no processing energy needed for stirring. Crop residues and food industry waste can be utilized in solid state anaerobic reactor to increase the biogas production. Due to its lower water content, the digestate of SS-AD can be used as fertilizer and pelletized fuel, so it is much easier to handle than the effluent of LAD. Disadvantage of SS-AD systems are requirement of larger amounts of inoculum and longer retention time. If solid state (SS-AD) anaerobic reactor is integrated with LAD, it will solve the problem of effluent disposal of LAD as well as SS-AD requirement of large amount of inoculum. The digestate comes from the SS-AD, which has no problem of odor issue can be used in the farm for fertilizing the land. Process simulation of LAD integrated with SS-AD is fairly new. The goal of this work is to expand the dynamic anaerobic reactor model to improve its ability and simulate continuous liquid anaerobic reactor designs and continuously feed the SS-AD where crop residues and other solid waste are digested. An accurate computer simulation process of the digestion kinetics were developed using SuperPro design software. Organic wastes from corn stover had been used in the simulated process of 
integrated SS-AD with LAD of dairy manure. It is shown in the simple block diagram and SuperPro process simulation flow diagram given in Fig.2.

\section{Results and Discussion}

\subsection{SuperPro simulation model of liquid state anaerobic digestion of dairy waste}

\subsubsection{Kinetics of organic matter hydrolysis in the simulated LAD model}

Fig. 3 shows the degradation rate curve of carbohydrate and protein with three different volatile solid percentages plotted against hydraulic retention time in days. These curves were obtained from the simulated SuperPro LAD process model for hydrolysis function using the rate constants given in Table 2. These figures show that carbohydrate degradation is faster than the protein degradation and also show that high volatile solid (VS) concentration gives higher degradation rate than the low concentration. About $50 \%$ of the substrate degradation was obtained in 20 days, which is the normal retention time for LAD in practice (mesophilic condition). The protein degradation is comparable to the results of protein degradation model based on ADM1 (Anaerobic Digestion Model 1) model and batch experimental values obtained by Flotats et al. [21].

Along with substrate degradation in hydrolysis, the hydrolyzed product formation i.e., production of volatile fatty acid as the result of hydrolysis were also plotted in the Fig.3. It shows total volatile acids (propionic, butyric and acetic), acetic acid alone and ammonia production rate obtained from the simulated LAD process. Since acetic acid is the major volatile fatty acid in anaerobic digestion and it accounts more than $60 \%$ of total volatile fatty acids [22], its production rate is shown separately. During the protein degradation nitrogen is released in the form of ammonia. Fig. 3 also shows the ammonia released during the simulated hydrolysis process of protein which is comparable to the protein degradation and simultaneous ammonia 
release in previously published studies [21]. The acetic acid data corresponding to the initial volatile solid concentration of $62.34 \mathrm{~g} / \mathrm{L}$ is comparable to the experimental data published by Vavilin et al. [23]. They have done the experiment with dairy manure at $62 \mathrm{~g} / \mathrm{L}$ volatile sold (VS) concentration and plotted acetic acid concentration versus time. Using this as calibration data they validate the first order hydrolysis kinetic data for 100 and $31 \mathrm{~g} / \mathrm{L}$ concentration of volatile solids. The acetic acid profile shown in Fig. 3 was obtained from the SuperPro simulated hydrolysis process of dairy manure. The data plotted in this figure is closely compared to the data published by Vavilin et al. [23].

\subsubsection{Volatile Fatty acid degradation}

The commonly studied VFAs in anaerobic digestion systems are acetic acid, propionic acid and butyric acid. Acetic acid is reported as a precursor in anaerobic digestion for methane production and it results 70\% of total methane production [4]. In this reaction acetic acid is converted into carbon dioxide and methane by acetotrophic methanogens. Other VFAs such as propionic acid and butyric acid are converted to acetic acid before methane production. In general methane produced from acetic acid is considered as the most sensitive process [1]. Propionic acid is a common intermediate product found in anaerobic digestion. Accumulation of propionic acid inhibits the growth of some microbial species and methane production; however the significant inhibition on methane production occurred at concentrations of 5000 and $6000 \mathrm{mg}$ $\mathrm{COD} / \mathrm{L}$ [24]. Butyric acid is an intermediate product from fermentation of carbohydrate, protein or lipid found in anaerobic digestion along with acetic and propionic acids [20]. Butyric acid at the concentration of $1800 \mathrm{mg} / \mathrm{L}$ was shown to be beneficial to methane yield. The rate of conversion of VFAs to methane usually follows the order of acetic acid $>$ butyric acid>propionic acid. Kinetics of VFAs degradation is shown in Fig.4 (a). It is obtained from the SuperPro 
simulated LAD of dairy manure. Table 3 show the Monod kinetic constants obtained from previously published literatures which were used in the simulated LAD model [25]. The resulting VFAs degradation obtained from LAD simulated model versus digestion time is plotted in Fig.4 (a). The VFAs degradation values were compared with the experimental data in the already published literature for VFA degradation in dairy waste [26]. VFAs values obtained for the SuperPro simulated model are closely matching with experimental values at different time of digestion.

\section{Table 3}

Monod kinetic constants used in simulated SuperPro LAD model

\begin{tabular}{l|l|l|l}
\hline Substrate & Temperature, ${ }^{\mathbf{0}} \mathbf{C}$ & $\begin{array}{l}\mathbf{K}_{\mathbf{s}}-\text { Substrate } \\
\text { constant, } \mathbf{m g} / \mathbf{L}\end{array}$ & $\begin{array}{l}\mathbf{K}_{\mathbf{d}}-\text { Degradation } \\
\text { constant, } \mathbf{1 / h}\end{array}$ \\
\hline Acetic acid & 35 & 180 & 0.018 \\
Butyric acid & 35 & 42 & 0.0038 \\
Propionic & 35 & 15 & 0.00116 \\
\hline
\end{tabular}

\subsubsection{Biogas yield}

Organic manure stabilization occurs during the methanogenic phase by conversion of acetic acid into methane. Methane is insoluble in water and readily separates from the manure and leaves the system. Carbon dioxide is also produced and escapes as gas. In methanogenic phase very few substrates can act as energy sources for methanogenic bacteria and they are strict anaerobes to which oxygen is inhibitory. In this phase acetic acid, methanol, and hydrogen are used as energy sources by the various methanogens. Among these, acetic acid (acetate) and hydrogen serve as the major substrates for methane formation in the anaerobic digestion. Approximately $72 \%$ of the methane formed in the anaerobic digestion of dairy manure comes 
from acetate cleavage (aceticlastic bacteria); $\mathrm{CH}_{3} \mathrm{COOH} \rightarrow \mathrm{CH}_{4}+\mathrm{CO}_{2}$ (i.e., Acetic acid $\rightarrow$ Methane + carbon dioxide). The remaining $28 \%$ is result from reduction of $\mathrm{CO}_{2}(13 \%$ from propionic acid and $15 \%$ from other intermediates). Hydrogen is used as energy source by $\mathrm{CO}_{2}$ reducing methanogens; $\mathrm{CO}_{2}+\mathrm{H}_{2} \rightarrow \mathrm{CH}_{4}+\mathrm{H}_{2} \mathrm{O}$. Fig.4 (b) shows the biogas yield over the digestion time, simulated process through SuperPro for dairy manure. Biogas yield was obtained from VFA degradation process simulated using Monod kinetic constants, which contains $68.7 \%$ methane. Biogas yield given in Fig.4 (b) is closely comparable to the experimental results obtained by Hamed and Ruihong [27] for unscreened dairy manure. Liao et al. [28] studied the effect of methane production using screened and unscreened manure in a complexly mixed reactor at mesophilic condition and found that methane yield of screened manure was higher $(63.5 \%)$ than unscreened manure $(49.1 \%)$. In this study the methane yield over the digestion time was obtained using unscreened manure and compared with the results published by Hamed and Ruihong [27].

\subsection{SuperPro simulation model of solid state anaerobic digestion of corn stover}

\subsubsection{Corn stover pretreatment in SuperPro simulated process}

Study of structural changes of microcrystalline cellulose, cellulose linters of cotton and spruce pulp at various alkali concentrations ranged from 0-18\% was done by Ciolacu and Popa [29]. At $8.5 \%$ alkali $(\mathrm{NaOH})$ concentration, it was observed that reductions in the DP $(6.6 \%$ $18.2 \%)$ and $\mathrm{CrI}(7.5 \%-10.0 \%)$ for all three substrates. These structural changes are advantageous for the conversion of lignocellulose into simple sugars to enhance the anaerobic digestion of lignocellulose materials. Various pretreatment studies by Varga et al., [30] showed that 10\% $\mathrm{NaOH}$ pretreatment on corn stover gave reduction of 95.9\% lignin, $88.2 \%$ hemicellulose and 53.3\% cellulose. It showed significant modification in the composition of pretreated corn stover 
compared to untreated one. Also their study showed the sugar (glucose) release during alkali $(10 \% \mathrm{NaOH})$ treatment was $44.0 \%$. Therefore alkali pretreatment using $10 \%$ sodium hydroxide was used in the SuperPro process simulation. Table 4 shows the composition of corn stover before and after pretreatment in the simulated model SS-AD process. The results obtained from the simulation process shows the reduction of $89.28 \%$ lignin, $84.86 \%$ hemicellulose and $54.19 \%$ cellulose, also the sugar (glucose) release during alkali $(10 \% \mathrm{NaOH})$ treatment obtained in this simulated process is $46.32 \%$. All these values were very close and comparable with the result published by Varga et al., [30].

\section{Table 4}

Corn stover composition before and after alkali pretreatment

\begin{tabular}{l|l|l}
\hline Composition & Untreated corn stover (\%) & Pretreated corn stover (\%) \\
\hline Ash & 4.94 & 4.55 \\
Acetate & 2.82 & 2.56 \\
Biomass & 1.09 & 1.00 \\
Cellulose & 27.22 & 12.46 \\
Extractives & 4.49 & NA \\
Hemicellulose & 21.57 & 3.27 \\
Glucose & NA & 46.32 \\
Lignin & 15.25 & 1.64 \\
Protein & 3.01 & 2.73 \\
Water & 19.61 & 25.48 \\
\hline
\end{tabular}

\subsubsection{Simulated volatile fatty acid production in SS-AD using corn stover}


Before simulating the integrated SS-AD and LAD process, only SS-AD using corn stover was simulated. This process includes receiving corn stover, size reduction, alkali pretreatment then anaerobic digestion. Batch process was simulated to evaluate the volatile acid production with various retention times in SS-AD process. To model the volatile acid production in the anaerobic digester during acetogenesis process, kinetic constants were used from the recently published literatures of SS-AD [11]. The hydrolysis constant value used in the simulation process model was $\mathrm{k}_{\mathrm{hyd}}=0.034423 \mathrm{~h}^{-1}$. This constant was selected and slightly modified to obtain the simulated VFA production rates. Simulated VFA production rates were compared with the already published experimental values of VFA production using corn stover by Jian Shi et al., [31].

Fig.5 (a) shows the total VFA production rate and individual VFA production rate $(\mathrm{g} / \mathrm{L})$ plotted against hydraulic retention time in days. These curves were obtained from the simulated SuperPro process model for acetogenesis process. This figure shows that higher concentration of acetic acid. The butyric acid given here is the total of iso-butyric and butyric acid. The maximum production of VFAs was obtained during 10 to 20 days, which is similar to the result reported by Jian Shi et al., [31] for corn stover. The VFA production rate obtained from the simulated SuperPro model for anaerobic digestion of corn stover was compared to the experimental results showed by Jian Shi et al., [31]. The simulated results were very close to the experimental results with very negligible difference in acetic acid production between the published data and the simulated data in this work.

\subsubsection{Simulated biogas yield in SS-AD using corn stover}

Batch process was simulated to evaluate the biogas production with various retention times in SS-AD process. To model the biogas production in the anaerobic digester during 
methanogenesis process, kinetic constants were used from the published literatures on modeling of solid waste decomposition by Vavilin et al., [9]. The methanogenesis constant values used in the simulation process model were $\mathrm{k}=0.002292 \mathrm{~h}^{-1}$ and the substrate constant was $500 \mathrm{ml} / \mathrm{L}$. This constant was selected from the literature and slightly modified to fit the simulated biogas production rates. Simulated biogas production rates were compared with the already published experimental values of biogas production using corn stover by Li et al., [32]. Fig.5 (b) shows the total biogas production rate $(\mathrm{L} / \mathrm{kg}$ of volatile solids) plotted against hydraulic retention time in days obtained from the simulated SuperPro process model for methanogenesis process. This figure shows that higher biogas yield at around 10-12 days and later it started to reduce. The biogas production rate obtained from the simulated SuperPro model for anaerobic digestion of corn stover was compared to the experimental results showed by Li et al., and Zhu et al., [32, 33]. The simulated results of both biogas yield and accumulated methane yield (Fig.5 (c)) were very close to the experimental results with least difference between the published data and the simulated data in this work.

\subsection{SuperPro simulation model of integrated SS-AD and LAD system of corn stover and dairy manure}

\subsubsection{Simulated volatile fatty acid production}

To simulate the integrated SS-AD and LAD process, effluent of dairy manure from LAD process was mixed with pretreated corn stover then anaerobic digestion was carried. Batch process was simulated to evaluate the volatile acid production with various retention times as separately done in LAD and SS-AD process. Since there were no published kinetic models and constant were established for integrated SS-AD and LAD, the constants used in SS-AD and LAD were used for their respective substrate. Also the anaerobic digestion was simulated as single 
process with individual stoichiometric and kinetic values separately for the substrate of LAD effluent and pretreated corn stover. The hydrolysis constant value used in the simulation process of SS-AD model was $k_{\text {hyd }}=0.034423 \mathrm{~h}^{-1}$ and for LAD effluent values from Table 2 were used.

Fig.6 (a) shows the total VFA production rate and individual VFA production rate $(\mathrm{g} / \mathrm{L})$ plotted against hydraulic retention time in days. These curves were obtained from the simulated SuperPro process model for acetogenesis process of integrated anaerobic digestion. This figure shows that higher concentration of acetic acid and the butyric acid and it has given here as the total of iso-butyric and butyric acid. The trend of maximum production was obtained during 10 to 20 days as shown for corn stover later it started to reduce. By comparing the VFA production rate to SS-AD, there is not much difference in acetic acid production between SS-AS and integrated SS-AD. But total VFA is high in SS-AD and LAD integrated process than the single process of SS-AD and LAD as well; and this is due the higher production of butyric and propionic acid in the integrated process. This is due to the unused VFAs coming through LAD effluent. To compare the efficiency of integrated process in methane and biogas yield were obtained through process simulation and presented in the following section.

\subsubsection{Simulated biogas production}

Batch process was simulated to evaluate the biogas production with various retention times as in SS-AD and LAD process. To model the biogas production in the anaerobic digester during methanogenesis process, kinetic constants in Table 3 for LAD and the methanogenesis constant values used in the SS-AD of corn stover $\left(\mathrm{k}=0.002292 \mathrm{~h}^{-1}\right.$ and the substrate constant 500 $\mathrm{ml} / \mathrm{L})$ were used. That means simulation process kinetics were done separately for the composition obtained for LAD effluent and the hydrolyzed corn stover, and the integrated methane yield was obtained. Fig.6 (b) shows the total biogas production rate (L/kg of volatile 
solids) plotted against hydraulic retention time in days obtained from the simulated SuperPro process model for methanogenesis process of integrated SS-AD with LAD effluent. This figure shows that higher biogas yield at around 25 days and later it started to reduce. The biogas production rate obtained from the simulated SuperPro model for integrated process was compared with the result obtained for LAD model and SS-AD model. Biogas yield obtained from all three simulated process of LAD, SS-AD and integrated systems were given in Fig.6 (c). The biogas yield pattern in integrated is similar to SS-AD; however the biogas yield is comparable to LAD. The total methane yield obtained for integrated process was about $75.1 \%$, which is more than LAD (68.7\%) and SS-AD (62.5\%) alone.

The result obtained from the SuperPro process simulation models were well comparable with the experimental results that were published already. Integrated process of SS-AD with LAD effluent in order to get the benefit of both the process as discussed early has been simulated using SuperPro process simulation tool. The anaerobic digestion was applied to the treatment of LAD effluent by integrating with SS-AD process with significant improvement in biogas production. The simulated process showed efficient yield of biogas and methane. The first order kinetics had been traditionally used to explain the hydrolysis process in anaerobic digestion, thus it was applied in the process simulation. However, hydrolysis of complex substrate is still could not be a general model with specific kinetic constants. So in this process simulation, the constant values were used form the already published literature with slight modification to fit in to model and the results were found close to the experimental results published earlier. Hence, the proposed simulation model is suitable and applicable to study the anaerobic reactor performance for various waste materials in $\mathrm{LAD}, \mathrm{SS}-\mathrm{AD}$ and integrated SS-AD and LAD as well and find the conditions and process stability under various operational conditions. This process simulation 
model followed the systematic approach such as, 1) waste classification based on their composition, organic and inorganic compounds; 2) taking care of all important parameters and other factors that influencing the digestion process; 3) formulation of stoichiometry and kinetic models based on the waste composition. In this way, information and knowledge gained through decades of scientific research on the area of anaerobic digestion process of dairy waster and corn stover were fully utilized.

\section{Conclusion}

A systematic simulation models were developed and evaluated using SuperPro designer tool for LAD, SS-AD process of dairy manure and corn stover. The effort was focused on the overview of the most important models found in the literature for hydrolysis and volatile fatty acid degradation kinetics to acquire the knowledge of the fact that anaerobic digestion is a complex process and regulated by many factors. Also the simulation model showed in this work is applicable to study the anaerobic reactor performance for various waste materials as well to find the process stability under various operational conditions. Furthermore this article was mainly focused show that integrate LAD and SS-AD would improve the efficiency of biomethane production and reduce the effort that needed to dispose excess effluent comes from LAD. Also by integrating two models the final sludge comes after SS-AD could be directly applied to the filed as manure. In conclusion this article showed overall chemical kinetics occurred in LAD, SS-AD and integrated system as well. When the results obtained through simulation process compared with experiments values (already published literatures), both the results were matched very well. When kinetic parameters of both process were integrated and applied in the integrated LAD and SS-AD system, it showed more bio-methane yield than the individual systems. 


\section{Acknowledgement}

This project was financially supported by USDA NIFA Biomass Research and Development Initiative, Award no. 2012-1008-2032.

\section{References}

[1]. Pavlostathis SG, Giraldo-Gomez E (1991) Kinetics of anaerobic treatment. CRC Crit. Rev. Environ. Contr. 21: 411-490.

[2]. Gavala HN, Angelidaki I, Ahring BK (2003) Kinetics and modelling of anaerobic digestion process. Adv. Biochem. Eng. Biotechnol. 81: 57-93.

[3]. Hill CR (1977) An Introduction to Chemical Engineering Kinetics and Reactor Design. John Wiley and Sons, New York, USA.

[4]. Mountfort DO, Asher RA (1978) Changes in proportions of acetate and carbon dioxide used as methane precursors during the anaerobic digestion of bovine waste. Appl. Environ. Microbiol., 35: 648-654.

[5]. Fukuzaki S, Nishio N, Nagai S (1990) Kinetics of the methanogenic fermentation of acetate. Appl. Environ. Microbiol. 56: 3158-3163.

[6]. Vasiliev VB, Vavilin VA, Rytov SV, Ponomarev AV (1993) Simulation model of anaerobic digestion of organic matter by a microorganism consortium: basic equations. Water Res. 20: 633-643.

[7]. Shankaranand, V.S., Ramesh, M.V., \& Lonsane, B.K., 1992. Idiosyncrasies of solid-state fermentation systems in the biosynthesis of metabolites by some bacterial and fungal cultures. Process Biochemistry 27(1), 33-6. 
[8]. Mickelson MN (1972) Glucose degradation, molar growth yields, and evidence for oxidative phosphorylation in Streptococcus agalactiae. Journal of Bacteriology 109(1): 96-105.

[9]. Vavilin VA, Lokshina LY, Jokela J, Rintala J (2004) Modeling solid waste decomposition. Bioresource Technol. 94 (1); 69-81.

[10]. Angelidaki I, Sanders W (2004) Assessment of the anaerobic biodegradability of macropollutants. Rev. Environ. Sci. Biotechnol. 3 (2): 117-129.

[11]. Garcia-Heras JL (2003) Reactor sizing, process kinetics and modelling of anaerobic digestion of complex wastes. In: Mata-Alvarez, J. (Ed.), Biomethanization of the Organic Fraction of Municipal Solid Wastes. IWA Publishing, TJ International Ltd., Padstow, Cornwall, UK, pp. 21-62.

[12]. Vavilin VA, Rytov SV, Pavlostathis SG, Jokela J, Rintala J (2003) A distributed model of solid waste anaerobic digestion: sensitivity analysis. Water Sci. Technol. 48 (4): 147-154.

[13]. Christ O, Wilderer PA, Angerhofer R, Faulstich M (2000) Mathematical modelling of the hydrolysis of anaerobic processes. Water Sci. Technol. 41 (3): 61-65.

[14]. Simeonov I, Momchev V, Grancharo VD (1996) Dynamic modeling of mesophilic anaerobic digestion of animal waste. Water Res. 30: 1087-1094.

[15]. Ruel MS, Comeau Y, Ginestet P, Heduit A (2002) Modeling acidogenic and sulfatereducing processes for the determination of fermentable fractions in wastewater. Biotechnol. Bioeng. 80(5): 525-536.

[16]. Nweke Chinenyenwa Nkeiruka , Nwabanne Joseph Tagbo (2014). Continuous process design model simulation for the anaerobic digestion of vegetable oil wastewater. American Journal of Environmental Protection 3(5): 209-216. 
[17]. Tiehm A, Nickel K, Zellhorn M, Neis U (2001) Ultrasonic waste activated sludge disintegration for improving anaerobic stabilization. Water Res. 35: 2003-2009.

[18]. Tanaka S, Kobayashi T, Kamiyama K, Bildan M (1997) Effects of thermochemical pretreatment on the anaerobic digestion of waste activated sludge. Water Science and Technology 35: 209-215.

[19]. Eronen P, Osterberg M, Jaaskelainen AS (2009) Effect of alkaline treatment on cellulose supramolecular structure studied with combined confocal Raman spectroscopy and atomic force microscopy. Cellulose 16(2): 167-178.

[20]. Mittal A, Katahira R, Himmel M, Johnson D (2011) Effects of alkaline or liquid-ammonia treatment on crystalline cellulose: Changes in crystalline structure and effects on enzymatic digestibility. Biotechnol Biofuels 4(1): 41.

[21]. Flotats X, Palatsi J, Ahring BK, Angelidaki I (2006). Identifiability study of the proteins degradation model, based on ADM1, using simultaneous batch experiments. Water Sci. Technol. 54 (4): 31- 39.

[22]. Patni NK, Jui PY (1985) Volatile fatty acids in stored dairy-cattle slurry. Agric. Wastes 13: $159-178$.

[23]. Vavilin VA, Fernandez B, Palatsi J, Flotats X (2008) Hydrolysis kinetics in anaerobic degradation of particulate organic material: An overview. Waste Management 28: 939-951.

[24]. Hyun SH, Young JC, Kim IS (1998) Inhibition kinetics for propionate degradation using propionate-enriched mixed cultures. Water Science and Technology 38(8): 443-451.

[25]. Lawrence AW, McCarty PL (1969) Kinetics of methane fermentation in anaerobic treatment. J. Wat. Poll. Cont. Fed. , 41: R1-R17. 
[26]. Aguilar A, Casas C, Lema JM (1995) Degradation of volatile fatty acids by differently enriched methanogenic cultures: Kinetics and inhibition. Water Research 29(2): 505-509.

[27]. Hamed M. El-Mashad, Ruihong Zhang (2010) Biogas production from co-digestion of dairy manure and food waste. Bioresource Technology, 101(11): 4021-4028.

[28]. Liao PH, Lo KV, Chieng ST (1984) Effect of liquid solids separation on biogas production from dairy manure. Energy in Agriculture 3: 61-69.

[29]. Ciolacu D, Popa VI (2005) Structural changes of cellulose determined by dissolution in aqueous alkali solution. Cellulose Chemistry and Technology 39(3-4): 179-188.

[30]. Varga E, Schmidt AS, Réczey K, Thomsen AB (2003) Pretreatment of corn stover using wet oxidation to enhance enzymatic digestibility. Appl. Biochem. Biotechnol. 104: 37-49.

[31]. Jian Shi, Fuqing Xu, Zhongjiang Wang, Jill A. Stiverson, Zhongtang Yu, Yebo Li (2014) Effects of microbial and non-microbial factors of liquid anaerobic digestion effluent as inoculum on solid-state anaerobic digestion of corn stover. Bioresource Technology 157: $188-196$.

[32]. Li Y, Stephen Y Park, Jiying Zhu (2011) Solid-state anaerobic digestion for methane production from organic waste. Renewable and Sustainable Energy Reviews15: 821-826.

[33]. Zhu Jiying, Cai Wanxia, Li Yebo (2010). Enhanced solid-state anaerobic digestion of corn stover by alkaline pretreatment. Bioresource Technology 101: 7523-7528. 


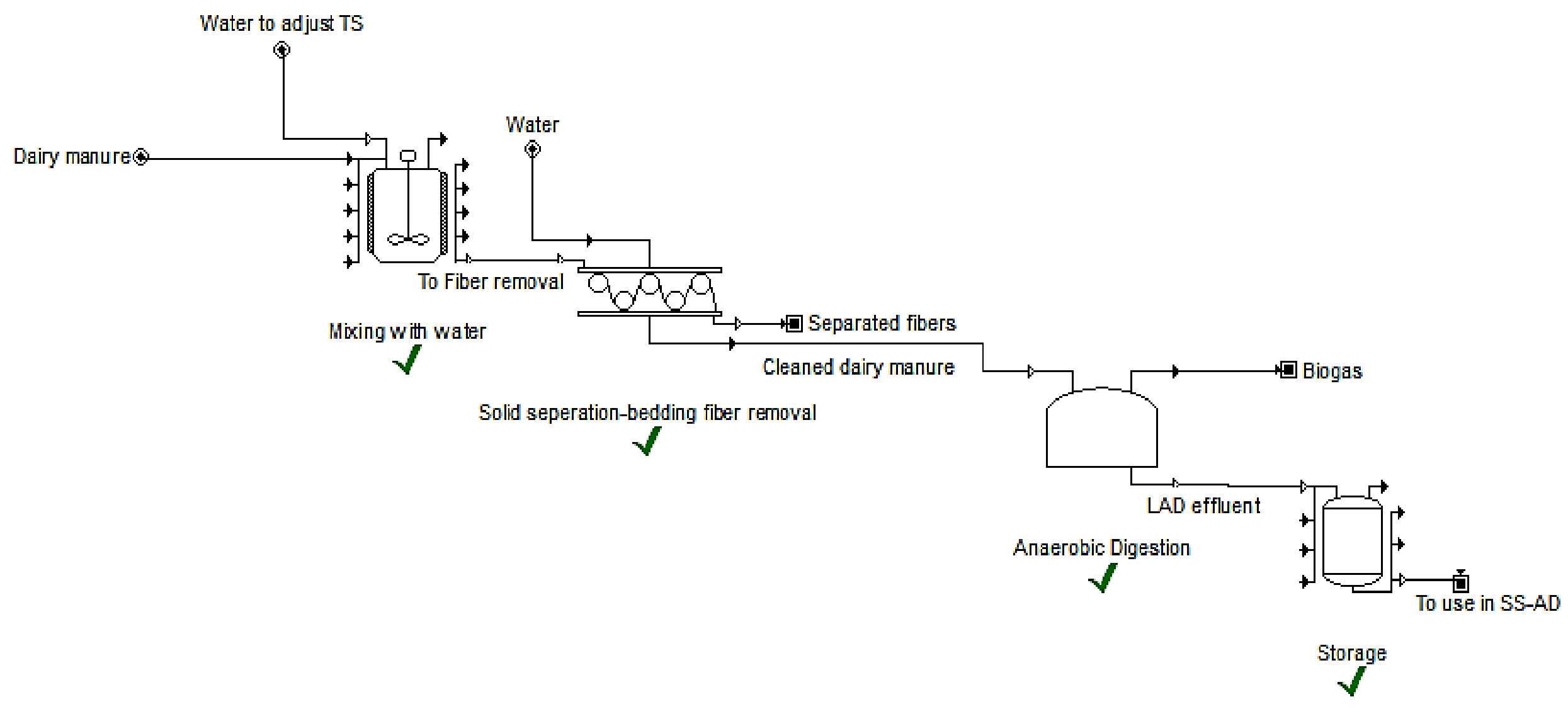




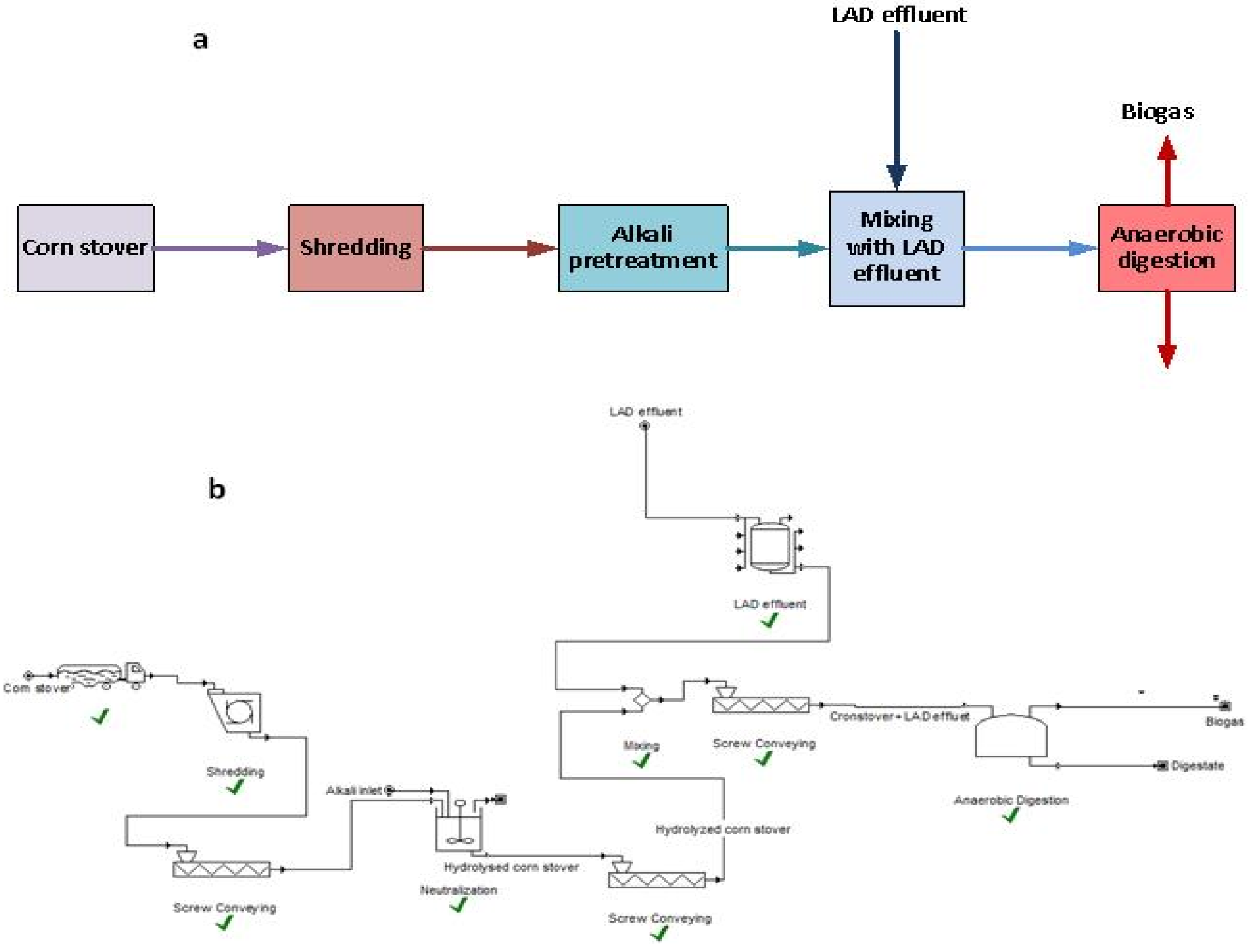



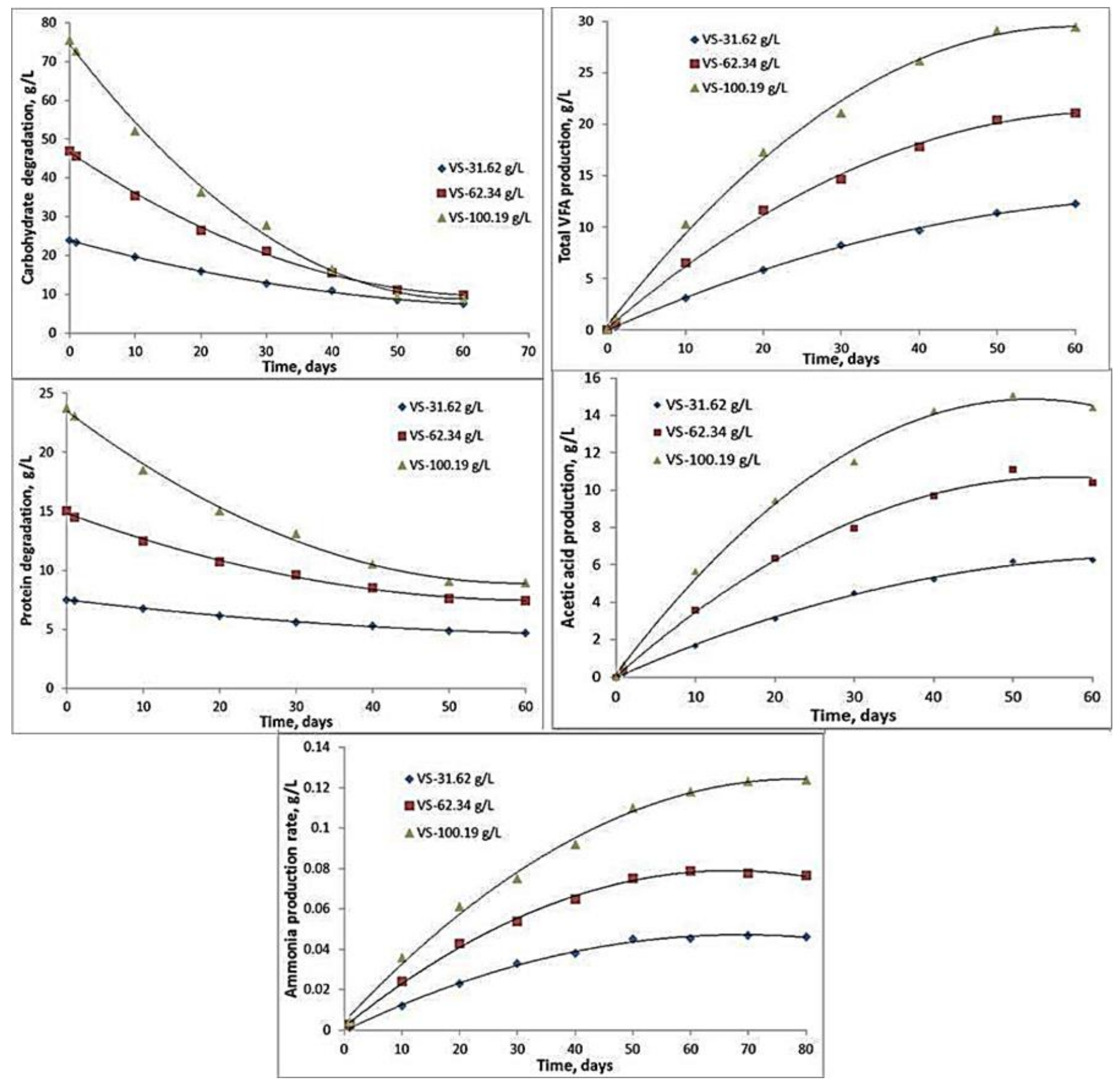


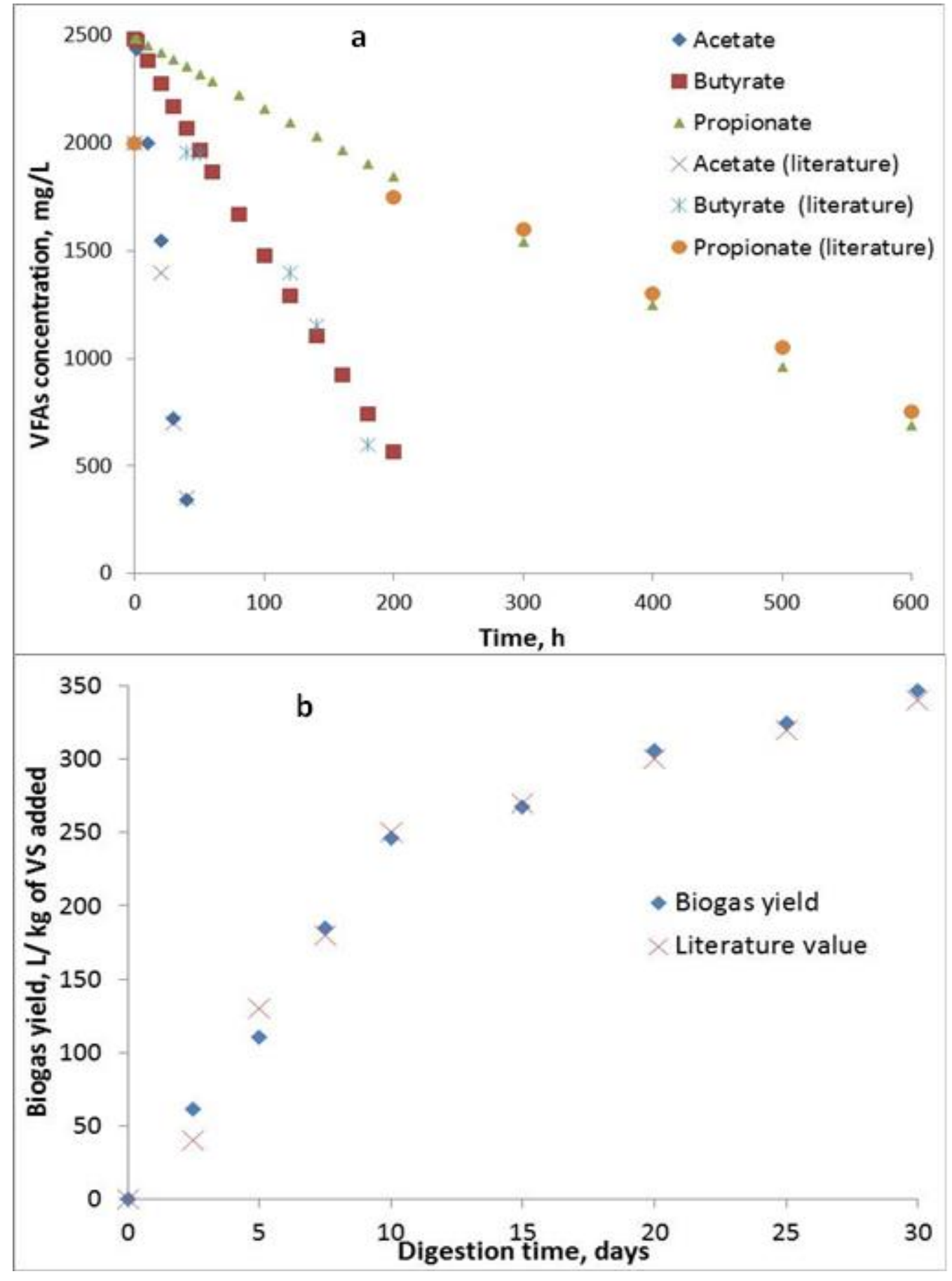



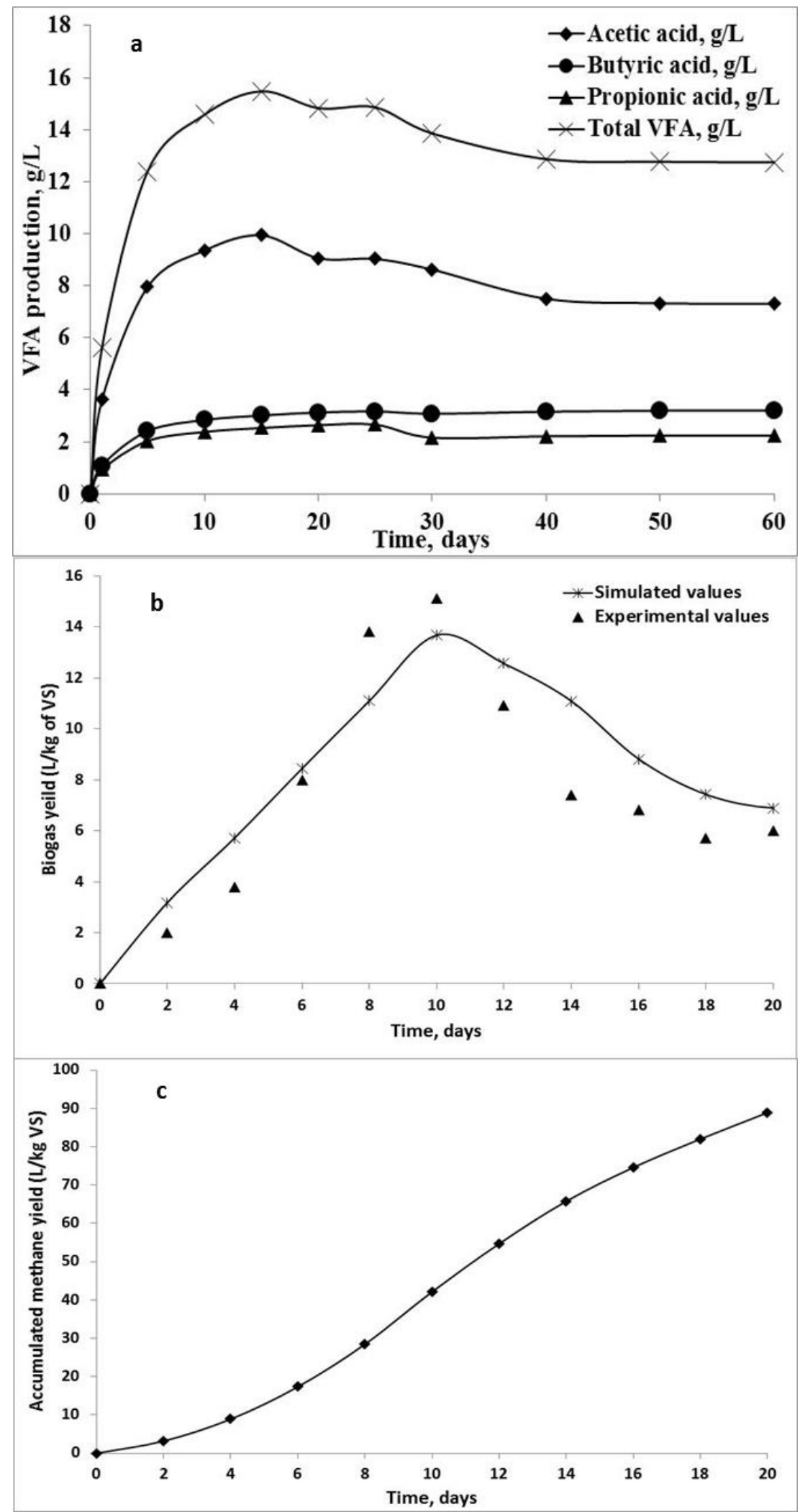

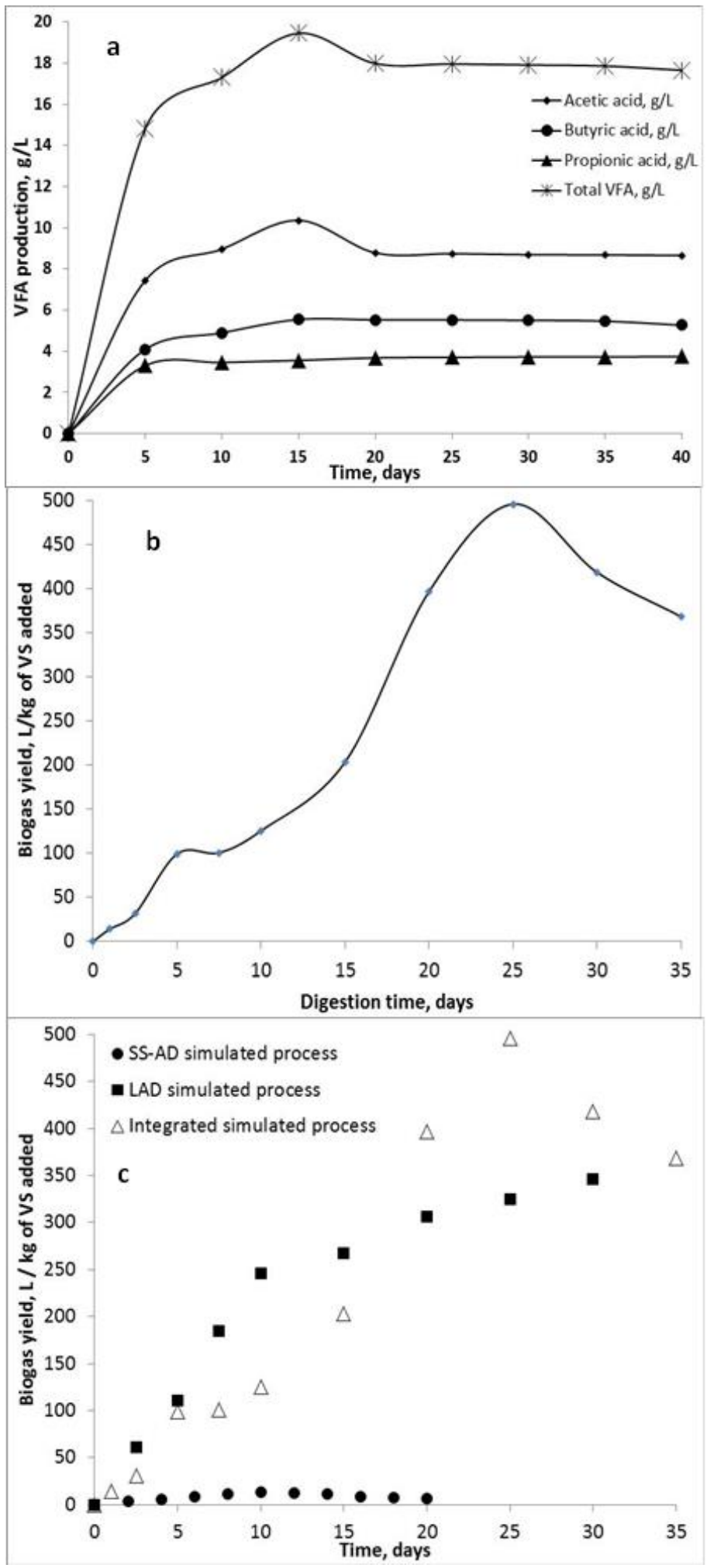
Graphical Abstract

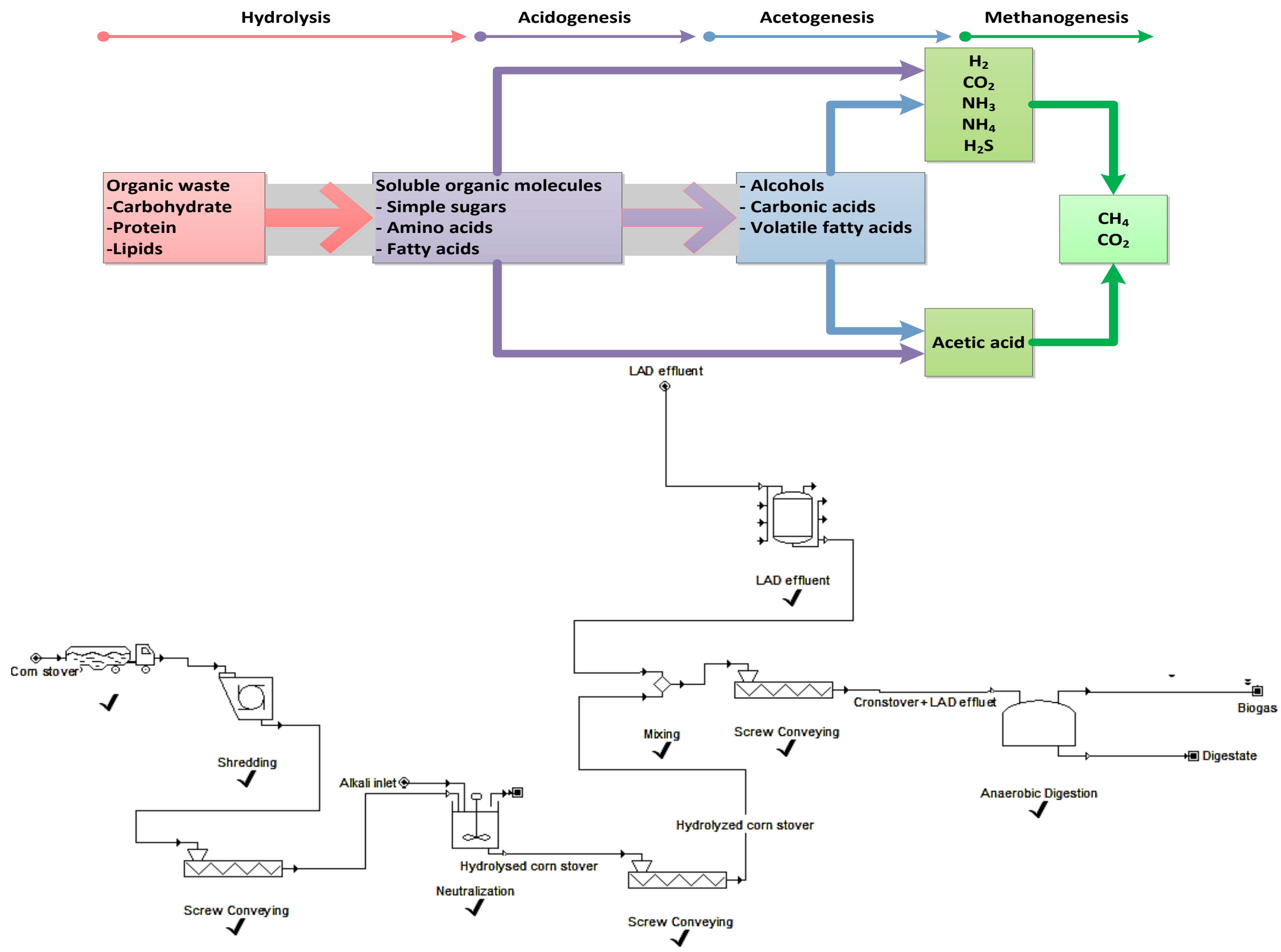

